\title{
First Thoughts on a New Era for JACM
}

\author{
John Weeks
}

\section{Dear JACM readers:}

I AM EXCITED TO JOIN with you for the beginning of a new era for The Journal of Alternative and Complementary Medicine $(J A C M)$. We plan to push the boundary of what a peer-reviewed "CAM" journal can mean for health and medicine. This column outlines some of my early, amendable thinking. Let me know your thoughts and responses.

I started May 1, 2016, following much deliberation after a surprising invitation to serve as editor-in-chief. I am listening, learning, and formulating. What I can share now is that my own work in this field ${ }^{1}$ is at the convergence of three major, interrelated explorations: the "modalities, systems, and disciplines" of integrative health and medicine in the U.S. NIH National Center for Complementary and Integrative Health framework ${ }^{2}$; the "products, practices, and practitioners" of traditional medicine in the WHO formulation $^{3}$; and the efforts to transform the dominant medical industry into a system that focuses on health and well-being. The "front of the book" - see below-will explore research dimensions of these trends.

My work over the past 32 years in these fields has focused on opening doors and reshaping boundaries. Research on Practice, Paradigm and Policy, as JACM's founding editors wisely chose to frame the Journal's mission, is foundational. I envision this journey as a 10-year commitment-si las diosas quierren, Inshallah, God willing. Lasting positive impact takes time. What are the ways a journal can have meaning in fostering optimal health? Do you have ideas? Publishing top-quality scientific research remains JACM's core business and my own mission. We will also work around the edges, as described below.

My personal desire is that this Journal be increasingly useful to ever broader circles of researchers, clinicians, educators, policy makers, and others discovering strategies for developing top-quality integrative care. I invite you to participate in this new phase of JACM's journey.

\section{Methods: The Front of the Book}

Our core method for success is to draw ever stronger and more impactful articles to the Journal. We are beginning internally with a thorough audit of journal processes. The Journal has been without an editor in chief for two years. Susan Jensen, who I am pleased will continue as managing editor, has had the tough job of taking the reins in the interim. We have work to do. I have heard thoughtful criticism and suggestions from new and old colleagues about bettering JACM's processes and product. Keep the suggestions coming! We are working on these. I welcome your feedback and ideas on your experience, good or bad. If we don't hear your concerns, how can we respond?

The new $J A C M$ will utilize an important new strategy for drawing energy and creating community. We will begin to use the first 3-10 pages in "the front of the book" to capture and explore critical questions in the field. What are the research topics on which you wish to comment to this community? In the United States, for instance, multiple efforts are under way to reshape pain care and confront the epidemic of opioid abuse. What are the important research questions begged by the emerging policy directions? What are the policy dimensions on leading research issues? Are we sufficiently engaging fundamental paradigm challenges?

You will begin to witness - and I hope participate in-the multiple methods we will use to get at these questions. Among these are guest commentaries, point-counterpoint, individual and two-person or three-person interviews, roundtables, and my own perspectives. I have already had the pleasure of beginning to cook up ideas with some of you. I am putting my experience in listening, curating, and convening to work. The best ideas will come from you. What pressing issues need to be addressed in the context of the mission of this scientific Journal?

This work is about building, shaping, and strengthening community. I had the pleasure and honor to serve on the organizing committee for the recent International Congress on Integrative Medicine and Health (ICIMH). JACM was congress partner and published the abstracts. That May 1720 gathering was all the evidence that anyone needs about how much researchers can enjoy community! What a pleasure it was to join researchers from 29 nations while representing JACM, with our readership reaching 170 nations. The heart of this Journal will continue to be-with your help! - an increasingly strong body of scientific work. Send your own work and that of your colleagues our way!

\section{Content: Three Major Interrelated Explorations}

The year 2016 is an unprecedented time for three movements in health and medicine. In the United States and Europe, what was once "complementary and alternative" is now mainly framed as "integrative health and medicine." Around the world, with the backing of the WHO Traditional Medicine Strategy 2014-2023, the integrative intention is

Editor-in-Chief, The Journal of Alternative and Complementary Medicine. 
similar, but the language different. There, we are seeking the best use of traditional medicine "products, practices, and practitioners" in meeting the WHO goal of primary care for all. Each is a profoundly "integrative" effort.

$J A C M$ welcomes contributions from, and has historically produced publications from, researchers who are principally identified with each of these movements. My experience is that these two integrative strains are not yet well connected. Although deeply embedded in the integrative care movement, I only began to fully awaken to the importance and integrative potency of the WHO work after being asked to participate in two of the four WHO planning meetings. These two were held in Hong Kong, leading to the 2014-2023 strategic plan. In her plenary at ICIMH, JACM Editorial Board member Heather Boon, $\mathrm{BScPhm}, \mathrm{PhD}$, shared a slide that spoke to the WHO plan. A good start to begin to bring this work forward. Yet much of the "global" content of the conference was still Eurocentric and old British Commonwealth. In 2017, the World Congress on Integrative Medicine and Health will explore this interconnection further. The conference, planned for May 3-5, 2017, in Berlin has a traditional medicine committee led by one of the WHO plan's lead authors, Torkel Falkenberg, PhD, and on which I am serving. We aim to strengthen the weave. Consider attending!

The JACM "front of the book" will explore research efforts in each of these arenas while also fostering greater interactivity between the two. Under WHO guidance, multiple national institutes and agencies are being created around the world to understand the value of traditional medicine "products, practices, and practitioners." Might there be roles, for instance, for new interinstitutional relationships between these and the established integrative medicine programs in academic health centers and other integrative health programs and agencies? A new Pan American Health Organization (PAHO)-involved initiative in Nicaragua, with which new JACM Editorial Board member and my adviser Daniel Gallego-Perez, MD, is connected, may be a model. ${ }^{4}$ In a column last year for Global Advances in Health and Medicine, ${ }^{5}$ I explored the uptake of the "integrative" term around the world. How might these worlds better intersect?

The Journal, in this next phase, will support us creating a global community of researchers interested in an evidenceinformed "good medicine" toward which we are all aiming. We will do so in the context of multinational efforts, noted at the top of this column, to enhance a focus, throughout medicine and in our communities, on health and well-being. In the United States we are beginning to see welcome signs of a convergence. I had a chance to share some of this convergence recently in a guest lecture to students in the Masters in Physiology-Complementary and Alternative Medicine program at Georgetown University. ${ }^{6}$ I was invited by new JACM adviser Aviad (Adi) Haramati, PhD. I shared related content in an oral poster session at ICIMH. ${ }^{7,8}$ The exciting potential was underscored by the ICIMH kick-off from neuroscientist Richard Davidson, $\mathrm{PhD}$, and by the follow-up segment on the microbiome. Davidson, the University of Wisconsin researcher, is now in his third decade of work on outcomes that focus on compassion, health, and well-being with his "inspirer in chief," the Dalai Lama. Traditional medicine strategies to "remove obstacles to cure and aid the healing power of nature," as captured in the

naturopathic healthcare tradition, are being affirmed by the most exotic of new scientific developments.

\section{Editorial Team: Welcome Some New (and Renewed) Members}

To do this work, I am building the editorial team. I am honored to share with you some colleagues and friends whom I have asked to join me as close advisers on this journey, and to help fill my own skill gaps. I was able to touch base with many at the recent ICIMH. Join me in welcoming them-or in the cases of those with an asterisk $(*)$, for their renewed commitment. They know that I will regularly be using them, and others, individually and as a group, as collective guidance and sounding board as we set our course.

Ather Ali, ND, MPH
Heather Boone,
BScPhm, PhD*
Dan Cherkin, PhD
Jeff Dusek, PhD
Daniel Gallego-Perez, MD
Paula Gardiner, MD, MPH
Michael Goldstein, PhD
Richard Hammerschlag, PhD
Adi Haramati, PhD
Patricia Herman, ND, PhD
Wayne Jonas, MD*
Darshan Mehta, MD, MPH

Over the next few months, I will be connecting with present members of the editorial board to explore ongoing relationships. Some have already reached out. I thank you each for your service to the Journal and look forward to your ideas about this next step on the journey.

\section{Naming: Shall We Keep the "Alternative and Complementary" Title?}

When Mary Ann Liebert's vice president, Vicki Cohn, invited me to this position, she put the name of the Journal on the table. Many people have strong opinions: Ditch "alternative." Add "integrative." Susan Jensen reported multiple requests at the JACM booth at ICIMH to make these changes. I am sympathetic to much of this. Better describe something by what it is than what it is not. Vicki has shared that changing a journal's name is a major undertaking. The transition takes at least 6 months of planning and then takes hold in a new calendar year. Thus, to change in 2017 would require a decision in a month.

That's too fast. We will only be doing this once-if we do it-in my envisioned 10 years here. So let's draw a collective deep breath on this. I added new editorial board member Ruth Westreich as a consumer/patient member following the Patient-Centered Outcomes Research Institute's urging to listen better to patient voices. Ruth's is a strong one. She suggests a convening to explore the best name. Such a gathering might inform our decision. I posted a column on The Huffington Post that stimulated some ideas. ${ }^{9}$ The subject will be alive over these next 12 months as we think forward to a possible name change for January 2018. Your ideas are welcome, even those that are only fabricated to create humorous and off-color acronyms. At least two of my esteemed advisors have already 
produced in the latter department, following my own off-color lead. These did not make it through peer review and thus cannot be included in this column.

For these next 18 months, here are some operational definitions for "complementary" and "alternative" in the Journal title. "Complementary" is a term I will always like as a clinical expression of the move in healthcare for interprofessionalism and teams - of practicing and learning "with, from, and about each other." It doesn't mean one always adorns another's tree. Each complements the other as we seek to create the optimal therapeutic order.

I offer the following as a vision for "alternative medicine" as reflected in the title: "reaffirms the importance of the relationship between practitioner and patient, focuses on the whole person, is informed by evidence, and makes use of all appropriate therapeutic and lifestyle approaches, healthcare professionals, and disciplines to achieve optimal health and healing." Isn't this a massive "alternative" to the care most people receive today? This happens to be the definition of Integrative Medicine and Health of the Academic Consortium for Integrative Medicine and Health. ${ }^{10}$ This also pretty well captures what I thought I was getting into when I started in this field in 1983. For the time being and going forward, this will be the declared JACM meaning of "alternative medicine."

\section{An Arbiter of the Conversation and Content Shaping Healthcare}

My invitation to you is this: Imagine, as the era of interprofessionalism and of inclusion of integrative health and traditional medicine expands, that this Journal becomes an arbiter of the conversation and content that shapes the course of healthcare.

With success, we will be drawing others to our conversations, and to our work-which is, after all, about good medicine and health. This is my commitment. This will take time. This will take an ever-growing village. It will take your best suggestions and contributions.

We are setting our course via the strategy defined by the team of Fredi Kronenberg, $\mathrm{PhD}$, Marc Micozzi, MD, PhD, and Kim Jobst, MD, who led JACM's original editorial work over 20 years ago: Research on Practice, Paradigm and Policy.

Last but not least, gratitude. My thanks to Vicki for her out-of-the-box decision to surprise me in early April with the offer to serve, and to Susan for guiding me into the job. Most of all, right now, thanks to each of you for your contributions to JACM over the past two decades. Thanks to each of you who have and will submit, recommend, review, advise, and cajole. You are JACM's life-blood. The Journal is in good shape. Now, to use the language Vicki gave me when she offered me the position, "It's time to take it to a new level."

Let's do it! Please get in touch with your ideas.

\section{References}

1. Weeks J. www.johnweeks-integrator.com (accessed May 27, 2016).

2. United States Congress. Title VI-National Center for Complementary and Alternative Medicine, pp. 388-390. USA Public Law 105-277-Oct. 21, 1998112 STAT. 2681. www.gpo.gov/fdsys/pkg/PLAW-105pub1277/pdf/PLAW105pub1277.pdf (accessed May 27, 2016).

3. WHO Traditional Medicine Strategy 2014-2023.

4. Weeks J. PAHO initiates Nicaragua initiative on integrative, traditional, and complementary therapies with US, Australian, and Spanish partner organizations. The Global Integrator Blog, Global Advances in Health and Medicine, January 6, 2016. www.gahmj.com/page/PAHO-InitiatesNicaragua-Initiative-on-Integrative-Traditional-and-Comple mentary-Therapies-with-US-Australian-and-Spanish-PartnerOrganizations (accessed May 27, 2016).

5. Weeks J. In name and concept: The global uptake of the movement for integrative medicine and health. Global Adv Health Med 2015;4:7-9.

6. Georgetown University. Calendar of Events: MS in Physiology-Complementary and Alternative Medicine. April 19, 2016: "Convergence in Health Creation? Four Eras in the Emergence of Integrative Care." https://cam.georgetown .edu/calendar-and-events (accessed May 27, 2016).

7. Weeks J, Olejownik J, Ring M, Dusek J. Oral Abstract 10.02. The movement toward values-based medicine and the triple aim: Is it increasing interest in integrative health services? International Research Congress on Integrative Medicine and Health. http://online.liebertpub.com/doi/full/ 10.1089/acm.2016.29003.abstracts

8. Weeks J, Olejownik, J, Ring M, Dusek J. Survey of health system integrative clinics regarding changes in inclusion following incentive shifts fostered in the Affordable Care Act. Project for Integrative Health and the Triple Aim, Center for Optimal Integrative. Academic Collaborative for Integrative Health. http://optimalintegration.org/pdfs/ pihta/PIHTA_Survey_of_Integrative_Centers_Post_ACA_ Incentive_Shifts_2014.pdf (accessed May 27, 2016).

9. Weeks J. In defense of alternative medicine. The Huffington Post, May 10, 2016. www.huffingtonpost.com/johnweeks/in-defense-of-alternative_b_9881056.html (accessed May 17, 2016).

10. Academic Consortium for Integrative Medicine and Health. Definition of integrative medicine and health. http://imcon sortium.org/about/about-us.cfm (accessed May 17, 2016).

Address correspondence to: John Weeks Academic Collaborative for Integrative Health Seattle, WA 98116

E-mail: jweeks.jacm@gmail.com 